\title{
Effect of Diatomite and Basalt Fibers on Pavement Performance and Vibration Attenuation of Waste Tires Rubber-Modified Asphalt Mixtures
}

\author{
Chunli Wu, ${ }^{1}$ Liding Li $\mathbb{D}^{1},{ }^{1}$ Yongchun Cheng, ${ }^{1}$ Zhengwei Gu $\mathbb{D}^{1},{ }^{1}$ Zehua Lv $^{2}$ Renbing Wang, $^{3}$ \\ and Baigeng Guan ${ }^{3}$ \\ ${ }^{1}$ College of Transportation, Jilin University, Changchun 130022, China \\ ${ }^{2}$ Hebei Provincial Communications Planning and Design Institute, Shijiazhuang 050011, China \\ ${ }^{3}$ Jilin Shengda Highway \& Bridge Construction Co., Ltd., Jilin 132200, China \\ Correspondence should be addressed to Zhengwei Gu; gzw@jlu.edu.cn
}

Received 8 September 2020; Revised 23 October 2020; Accepted 26 October 2020; Published 20 November 2020

Academic Editor: Fulu Wei

Copyright $(2020$ Chunli Wu et al. This is an open access article distributed under the Creative Commons Attribution License, which permits unrestricted use, distribution, and reproduction in any medium, provided the original work is properly cited.

\begin{abstract}
As an eco-friendly pavement material, waste tires rubber-modified asphalt mixtures (WRMs) have been applied in pavement engineering widely. To further improve the performance and adaptability of WRM, diatomite and basalt fibers are, respectively, added to WRM. Subsequently, the Marshall tests, the rutting tests, the low-temperature splitting tests, the freeze-thaw splitting tests, and the vibration attenuation tests are conducted to study the effect of diatomite and basalt fibers on pavement properties of WRM. Furthermore, the correlation degree between the content of diatomite, basalt fibers, asphalt, and the pavement properties of WRM is analysed by the grey correlation grade analysis (GCGA). The results show that the addition of diatomite and basalt fibers can significantly improve the pavement and vibration attenuation properties of WRM. The improvement of high-temperature permanent deformation resistance, low-temperature cracking resistance, and water damage resistance of WRM is mainly attributed to diatomite, basalt fibers, and asphalt-aggregate ratio, respectively. The improvement of the vibration attenuation of WRM by diatomite and basalt fibers is mainly attributed to the increase of waste tires rubber-modified asphalt (WRA) content caused by adding diatomite and basalt fibers.
\end{abstract}

\section{Introduction}

With the increase of global car ownership, a large number of waste tires have been produced, which seriously pollutes the natural environment and occupies a large number of land resources. Recycling these waste tires is an urgent problem to be solved. Notably, it has become an effective method to deal with waste tires by using them in road engineering materials [1-4]. Using waste tires rubber (WR) in road engineering materials can not only protect the environment and save resources but also improve the mechanical properties of pavement materials and reduce vibration and noise on the road $[2,5-9]$. Some studies pointed out that the addition of WR to the asphalt mixtures could improve the performance of antideformation at high temperature and anticrack at low temperature [6,10-12]. And WR also enhanced the hightemperature performance of desulphurization gypsum residues modified asphalt mixtures [12]. In addition, the fatigue performance of WR modified asphalt mixtures (WRM) had been studied by using the semicircular bending tests and flexure beam tests, and the results showed that the WRM exhibited better fatigue performance compared to the nonreinforced mixtures [7, 13-15]. Moreover, WRM exhibited more excellent recoverable strain than the styrenebutadiene-styrene modified asphalt mixtures [16].

The application of WR in road engineering materials not only improves the engineering performance of asphalt mixtures but also has good environmental and economic benefits. In order to further improve the performance and adaptability of WRM and WR modified asphalt (WRA), 
many researchers had proposed some feasible solutions. Chen et al. [9] applied the reacted and activated WR to enhance the engineering performance of asphalt mixtures, and the results showed that, compared to the polymer modified asphalt mixtures, the reacted and activated WRM exhibited excellent low-temperature cracking resistance, high-temperature rutting resistance, fatigue cracking resistance, moisture susceptibility, and noise reduction. Gong et al. [17] reported that cement coated rubber aggregate had better bonding performance with asphalt and higher mechanical strength than untreated rubber aggregate. Liu et al. [18] introduced that the diatomite and WR compound modified asphalt exhibited better performance in short-term aging resistance than the diatomite modified asphalt and WRA. Maharaj et al. [19] claimed that the WR and polyethylene terephthalate compound modified asphalt presented excellent mechanical properties. Zhang et al. [5] pointed out that the WR and plastic compound modified asphalt mixtures had excellent fatigue resistance and rutting resistance. It can be concluded that, at present, many studies focused on adding organic and inorganic materials to enhance the performance of WRA and WRM. However, the addition of some organic modifiers raises the mixing and compaction temperature of WRM, thereby increasing the release of toxic gases such as xylene and toluene [20].

Therefore, in this paper, the diatomite and basalt fibers, two inorganic and eco-friendly reinforced materials, were used to enhance the performance of WRM. Subsequently, the effects of diatomite and basalt fibers' contents on the high-temperature permanent deformation resistance, lowtemperature cracking resistance, and water damage resistance of WRM were studied. Considering that rubber is an excellent damping material, it can be used to improve the vibration attenuation of asphalt mixtures. Accordingly, the effects of diatomite and basalt fibers' contents on the vibration attenuation of WRM were also studied and analysed by the vibration attenuation tests of the rutting plates and the tire.

In addition, the accelerometer was widely used to evaluate the performance of asphalt mixtures. Polaczyk et al. [21] used accelerometers to study the Marshall compaction process of asphalt mixtures. Real et al. [22] used the impact hammer excitation technology to evaluate the damping characteristics of asphalt mixtures. Biligiri [23] analysed the damping characteristics of asphalt mixture based on the data collected by accelerometer based on vibroacoustic technology and evaluated the noise reduction performance of asphalt mixture.

Furthermore, to analyse the internal cause of the effect of diatomite and basalt fibers on the pavement performance and vibration attenuation of WRM, the grey correlation degree analysis (GCGA) was performed to quantitatively calculate the correlation degree between the diatomite content, basalt fibers content, as well as asphalt-aggregate ratio (ratio of asphalt to mineral aggregate) and volume of air voids (VV), voids in the mineral aggregate (VMA), voids filled with asphalt (VFA), the pavement performance, and the vibration attenuation of WRM. This work can provide some references for the practical application and performance enhancement of WRM, and it can also help protect the natural environment and promote the development of sustainable technology.

\section{Materials and Methods}

2.1. Materials. In this paper, WRA was used as the binder to fabricate the asphalt mixtures. The WRA was prepared as the following processes. Firstly, the base asphalt A-90\# supplied by Panjin Petrochemical Industry was heated to $150-160^{\circ} \mathrm{C}$. Subsequently, the tire rubber powders with 40 mesh (particle size: $0.4 \mathrm{~mm}$ ) and $20 \mathrm{wt} . \%$ (weight ratio) of asphalt were added to the base asphalt at the temperature of $180^{\circ} \mathrm{C}$ for $30 \mathrm{~min}$ at a shear speed of $5000 \mathrm{rpm}$ [24-26]. The physical properties of the base asphalt and WRA were tested, and the test results are shown in Table 1. The diatomite and the basalt fibers originated from Changbai Mountain and the Jiuxin Basalt Industry Co., Ltd., respectively. Their properties are shown in Tables 2 and 3. The basalt aggregate with nominal maximum aggregate size $13.2 \mathrm{~mm}$, as shown in Table 4, was used to fabricate WRM, diatomite reinforced WRM (DWRM), and basalt fibers reinforced WRM (BWRM) according to Standard Test Methods of Bitumen and Bituminous Mixtures for Highway Engineering (JTG E202011) [27].

\subsection{Experimental Methods}

2.2.1. Asphalt Mixtures Preparation. In this study, three types of asphalt mixtures were prepared, namely, WRM, DWRM, and BWRM. The three types of asphalt mixtures were divided into seven groups: WRM, DWRM with 5 wt.\% diatomite, 7.5 wt.\% diatomite, and 10 wt.\% diatomite, BWRM with $0.2 \mathrm{wt} . \%$ basalt fibers, $0.3 \mathrm{wt} . \%$ basalt fibers, and 0.4 wt.\% basalt fibers, and the specific preparation scheme is shown in Table 5. The content of diatomite and basalt fibers is determined by the previous research [28-30]. According to Table 5, the diatomite (added in substitution to mineral filler), basalt fiber (relative to mineral mass ratio), WRA, and aggregate were mixed to prepare the standard Marshall specimens $(\phi 101.6 \mathrm{~mm} \times 63.5 \mathrm{~mm})$ and the rutting specimens $(300 \mathrm{~mm} \times 300 \mathrm{~mm} \times 50 \mathrm{~mm})$ for subsequent testing. All the samples were formed under the asphalt-aggregate ratio in the research. All the samples were fabricated with the optimum asphalt-aggregate ratio in the research [28].

\subsubsection{Volume and Mechanical Properties Tests.} According to JTG E20-2011, VV, VMA, VFA, Marshall stability (MS), flow value (FL), and pavement properties indexes of 7 groups of asphalt mixtures were tested and calculated [31]. The test processes are shown in Figure 1. The pavement properties of asphalt mixtures mainly include permanent deformation resistance at high temperature, crack resistance at low temperature, and water damage resistance. The high-temperature permanent deformation resistance is usually characterized by the value of dynamic 
TABle 1: Physical properties of asphalt.

\begin{tabular}{lcccc}
\hline Properties & A-90\# asphalt & & WRA \\
& Standard & Value & Standard & Value \\
\hline Density $\left(15^{\circ} \mathrm{C}, \mathrm{g} / \mathrm{cm}^{3}\right)$ & - & 1.016 & - & 1.025 \\
Penetration $\left(25^{\circ} \mathrm{C}, 0.1 \mathrm{~mm}\right)$ & $80-100$ & 91.6 & $60-100$ & 62.6 \\
Softening point $T_{\mathrm{R} \& \mathrm{~B}}\left({ }^{\circ} \mathrm{C}\right)$ & $\geq 45$ & 46.9 & $>50$ & 66.5 \\
Ductility $(\mathrm{cm})$ & $\geq 100\left(25^{\circ} \mathrm{C}\right)$ & $>150\left(25^{\circ} \mathrm{C}\right)$ & $\geq 10\left(5^{\circ} \mathrm{C}\right)$ & $20.9\left(5^{\circ} \mathrm{C}\right)$ \\
Elastic recovery $(\%)$ & - & - & $\geq 50$ & 74.3 \\
\hline
\end{tabular}

TABle 2: Properties of basalt fibers.

\begin{tabular}{lccccccc}
\hline Properties & $\begin{array}{c}\text { Diameter } \\
(\mu \mathrm{m})\end{array}$ & $\begin{array}{c}\text { Length } \\
(\mathrm{mm})\end{array}$ & $\begin{array}{c}\text { Water } \\
\text { content }(\%)\end{array}$ & $\begin{array}{c}\text { Combustible } \\
\text { content }(\%)\end{array}$ & $\begin{array}{c}\text { Tensile } \\
\text { strength }(\mathrm{MPa})\end{array}$ & $\begin{array}{c}\text { Tensile modulus of } \\
\text { elasticity }(\mathrm{GPa})\end{array}$ & $\begin{array}{c}\text { Elongation } \\
\text { at break }(\%)\end{array}$ \\
\hline Value & $10-13$ & 6 & 0.030 & 0.56 & 2320 & 86.3 & 2.84 \\
\hline
\end{tabular}

TABLE 3: Properties of diatomite.

\begin{tabular}{|c|c|c|c|c|c|}
\hline Properties & Particle size & Density & Bulk density & Color & $\mathrm{pH}$ \\
\hline Value & $<0.075 \mathrm{~mm}$ & $2.34 \mathrm{~g} / \mathrm{cm}^{3}$ & $0.34-0.41 \mathrm{~g} / \mathrm{cm}^{3}$ & White & 9.0 \\
\hline
\end{tabular}

TABLe 4: Aggregate gradation of AC-13.

\begin{tabular}{lcccccccccc}
\hline Sieve size $(\mathrm{mm})$ & 0.075 & 0.15 & 0.3 & 0.6 & 1.18 & 2.36 & 4.75 & 9.5 & 13.2 & 16 \\
\hline Percent passing & 4.8 & 8.3 & 12.2 & 18.6 & 25.8 & 33.9 & 54.8 & 80.9 & 94.8 & 100 \\
\hline
\end{tabular}

TABLE 5: The mix proportion scheme of seven groups of asphalt mixtures.

\begin{tabular}{|c|c|c|c|c|c|c|c|}
\hline Mixtures & WRM & \multicolumn{3}{|c|}{ DWRM } & \multicolumn{3}{|c|}{ BWRM } \\
\hline Diatomite content (\%) & 0 & 5 & 7.5 & 10 & 0 & 0 & 0 \\
\hline $\begin{array}{l}\text { Basalt fibers } \\
\text { content }(\%)\end{array}$ & 0 & 0 & 0 & 0 & 0.2 & 0.3 & 0.4 \\
\hline $\begin{array}{l}\text { Asphalt-aggregate } \\
\text { ratio (\%) }\end{array}$ & 5.10 & 5.25 & 5.35 & 5.45 & 5.27 & 5.38 & 5.50 \\
\hline
\end{tabular}

stability (DS), and the higher the value, the better the resistance permanent deformation at high temperature. The DS can be calculated according to equation (1) [27]. The resistance cracking at low temperature is usually reflected by the splitting tensile strain at $-10^{\circ} \mathrm{C}\left(\varepsilon_{T}\right)$. A greater $\varepsilon_{T}$ means that there is a better resistance cracking at low temperature. $\varepsilon_{T}$ can be calculated by equation (2) [27]. And equations (3) and (4) show the calculated method of splitting tensile strength $\left(R_{T}\right)$ and failure stiffness modulus $\left(S_{T}\right)$ at low temperature, respectively. The water damage resistance is usually characterized by the tensile strength ratio (TSR). A greater TSR means better water damage resistance. The TSR can be calculated by equation (5) [27]:

$$
\mathrm{DS}=\frac{\left(t_{2}-t_{1}\right) \times N}{d_{2}-d_{1}},
$$

where $N$ is wheel moving speed, 42 times/min, and $d_{1}$ and $d_{2}$ are the tracking depth at $t_{1}(45 \mathrm{~min})$ and $t_{2}(60 \mathrm{~min})$, respectively, mm:

$$
\begin{aligned}
\varepsilon_{T} & =\frac{Y_{T} \times(0.0307+0.0936 \times \mu)}{(17.94-0.314 \times \mu)}, \\
R_{T} & =\frac{0.006287 \times P_{T}}{h}, \\
S_{T} & =\frac{P_{T} \times(3.588-0.0628 \times \mu)}{h \times Y_{T}} .
\end{aligned}
$$

where $Y_{T}(\mathrm{~mm})$ is the total vertical deformation corresponding to the maximum breaking load $P_{T}(\mathrm{~N}) ; \mu$ is Poisson's ratio, which is 0.25 ; and $h$ is the height of Marshall specimens, $\mathrm{mm}$ :

$$
T S R=\frac{R_{T 2}}{R_{T 1}} \times 100,
$$

where $R_{T 1}$ and $R_{T 2}$ are the average tensile strength of frozenthawed specimens and original specimens respectively, $\mathrm{MPa}$.

2.2.3. Vibration Attenuation Tests of the Rutting Plates. The vibration attenuation tests of the rutting plates $(300 \mathrm{~mm} \times 300 \mathrm{~mm} \times 50 \mathrm{~mm})$ made of WRM, DWRM, and BWRM are shown in Figure 2. The test processes are as follows [22]. Firstly, the acceleration sensor was bonded to the center of the back of the rutting plate with the epoxy resin, and the other end of the acceleration sensor was well connected to DH5922 dynamic signal test and analysis system. Subsequently, the rutting plate with the acceleration sensor was bonded on two concrete blocks with the epoxy 


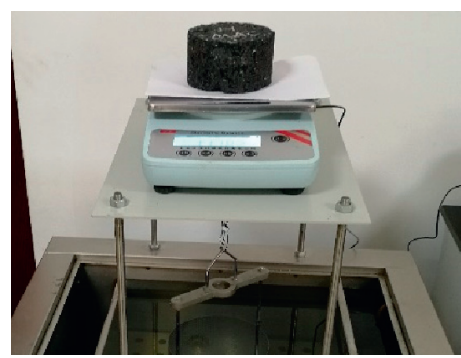

(a)

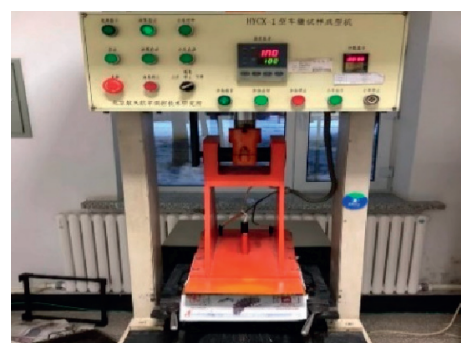

(d)

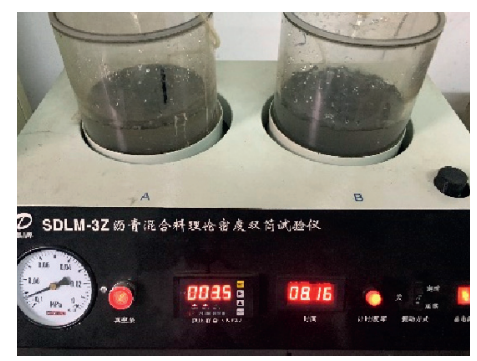

(b)

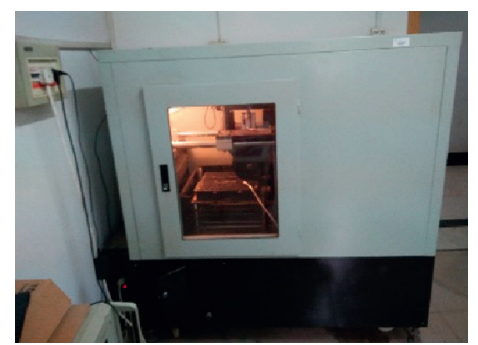

(e)

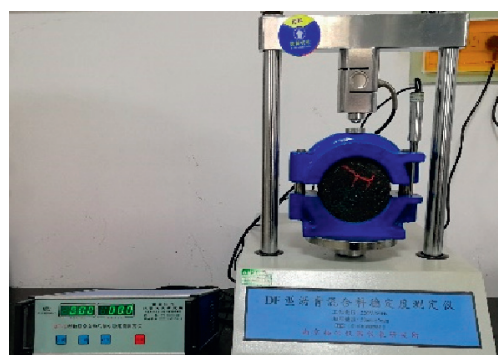

(c)

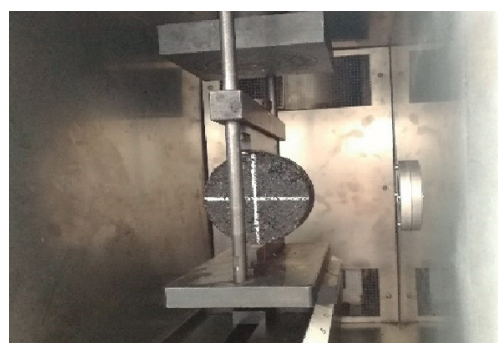

(f)

FIGURE 1: WRM performance tests: (a) bulk volume density tests; (b) theoretical maximum density tests; (c) Marshall stability tests; (d) rutting plate compaction; (e) rutting tests; (f) splitting strength tests.

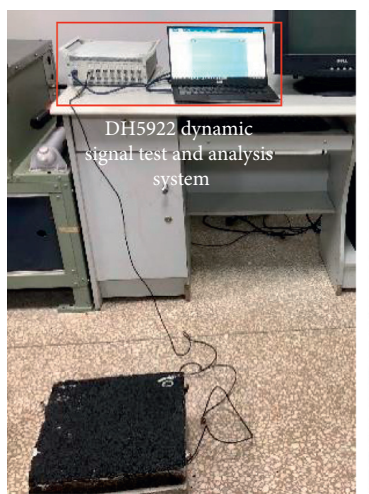

(a)

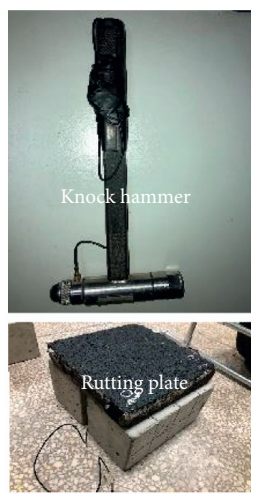

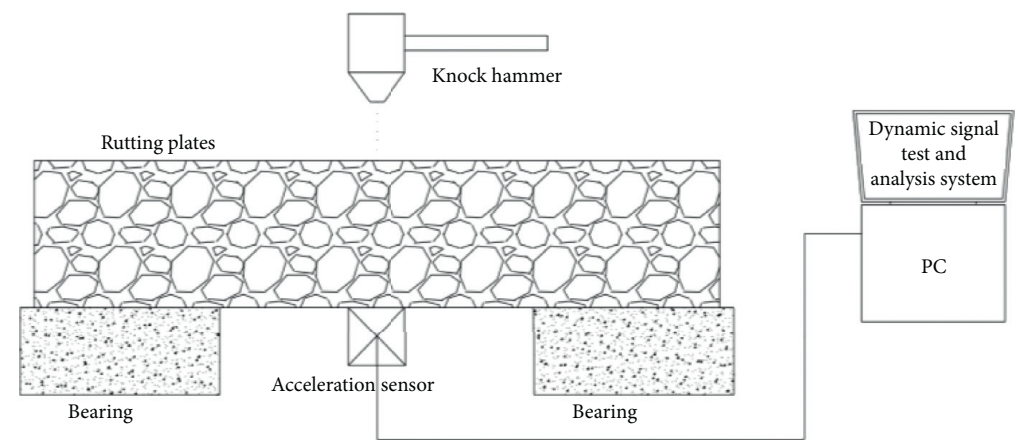

(b)

Figure 2: Vibration attenuation tests of the rutting plate: (a) factual picture and (b) schematic diagram.

resin and the movement of the rutting plate in the $x, y$, and $z$ directions restricted. Finally, the knock hammer with rubber head shown in Figure 2 was used to hit the center position of the front of the rutting plate, and the vibration attenuation signal of the rutting plate was collected by the acceleration sensor with a frequency of $2 \mathrm{kHz}$ and analysed by the DH5922 dynamic signal test and analysis system.

2.2.4. Free Vibration Attenuation Tests of Tire. The tire free vibration attenuation tests are shown in Figure 3. The vibration attenuation of tire on the asphalt mixtures was tested as the following processes [23]. Firstly, the acceleration sensor was connected with DH5922 dynamic signal test and analysis system, and the sensor was fixed on the Michelin tire $(250 \mathrm{kPa}, 195 / 60 \mathrm{R} 14)$ so that the sensor could measure the vertical acceleration of the tire. Subsequently, the tire with the acceleration sensor was placed $3 \mathrm{~cm}$ above the center of the standard rutting plate specimens bonded tightly with the rigid ground. Finally, the tire fell freely and vertically onto the rutting plate, and the vibration attenuation signal of the tire was collected by the acceleration sensor and analysed by the DH5922 dynamic signal test and analysis system.

2.3. Vibration Attenuation Model. To evaluate the vibration attenuation properties of the asphalt specimen and the tire on the asphalt specimen, the pavement and the tire are simplified as the tire-pavement vibration model as shown in Figure 4 . When the impact load is applied on the asphalt pavement and the tire, displacement $x$, velocity $\dot{x}$, and acceleration $\ddot{x}$ of vibration of the asphalt pavement and the tire conform to the relationship as shown in the following equation $[22,23,32,33]$ : 


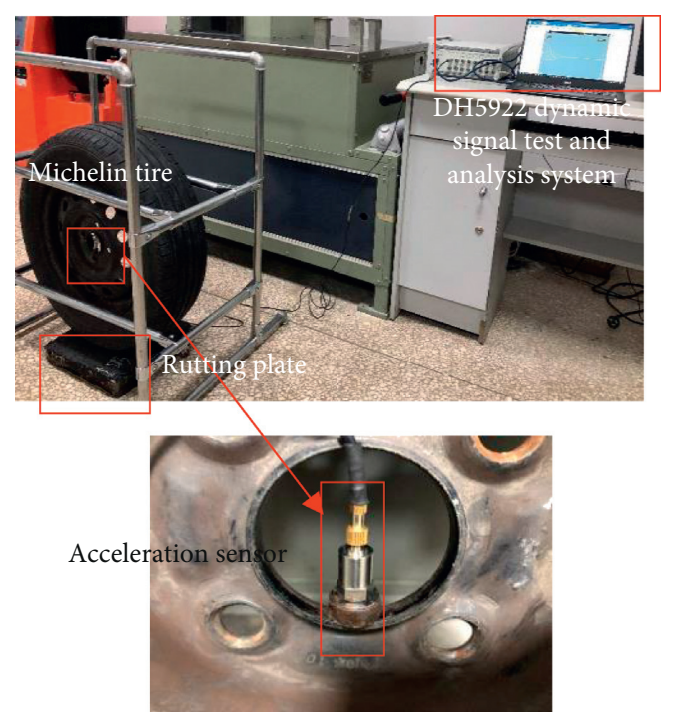

(a)

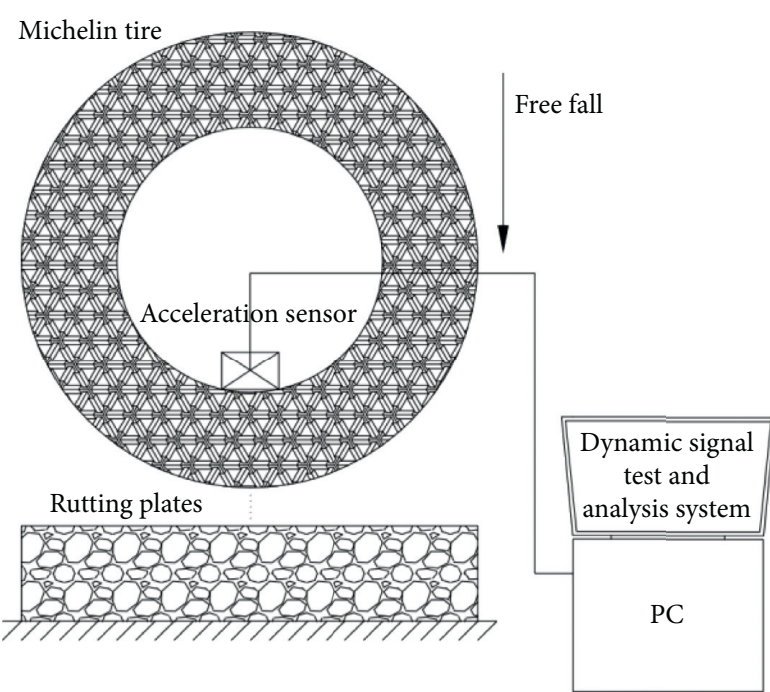

(b)

FIgURE 3: Tire free vibration attenuation test of asphalt mixtures: (a) factual picture and (b) schematic diagram.
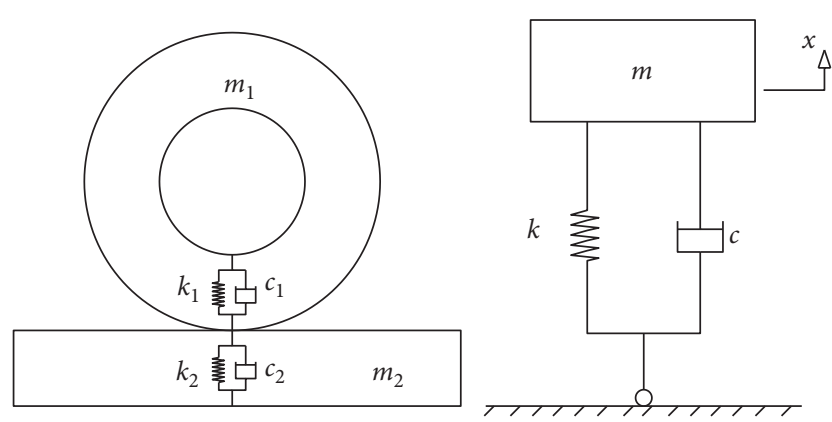

FIgURE 4: Tire and rutting plate vibration model.

$$
m \ddot{x}+c \dot{x}+k x=0
$$

where $m, c$, and $k$ are the equivalent vibration mass, stiffness, and viscosity coefficient of the asphalt pavement or the tire, respectively. Let $\omega_{n}^{2}=k / m$ and $\xi^{2}=c^{2} / 4 m k$, equation (4) can be written as the following equation:

$$
\ddot{x}+2 \xi \omega_{n} \dot{x}+\omega_{n}^{2} x=0,
$$

where $\omega_{n}$ is the circular frequency of system vibration and $\xi$ is the damping ratio of system vibration. It can be seen that the previous equation is the second-order linear homogeneous differential equation, and its characteristic roots are shown in equation (4).

$$
s=\omega_{n}\left(-\xi \pm \sqrt{\xi^{2}-1}\right) .
$$

Since the vibration attenuation of the tire and pavement is underdamped, $0<\xi<1$ can be obtained. Letting $\omega_{d}=\omega_{n} \sqrt{1-\xi^{2}}$, equation (6) can be further expressed as the following equation:

$$
s=-\xi \omega_{n} \pm i \omega_{d}
$$

Therefore, the solution of equation (5) is expressed as the following equation:

$$
\begin{aligned}
x(t) & =G_{1} e^{-\xi \omega_{n} t+i \omega_{d} t}+G_{2} e^{-\xi \omega_{n} t-i \omega_{d} t} \\
& =e^{-\xi \omega_{n} t}\left(G_{1} e^{i \omega_{d} t}+G_{2} e^{-i \omega_{d} t}\right) .
\end{aligned}
$$

According to the Euler equation (equation (9)), equation (8) can be written as equation (10):

$$
\begin{aligned}
e^{ \pm i \omega t} & =\cos \omega t \pm i \sin \omega t, \\
x(t) & =e^{-\xi \omega_{n} t}\left(A_{1} \sin \omega_{d} t+A_{2} \cos \omega_{d} t\right) \\
& =A e^{-\varepsilon t} \cos \left(\omega_{d} t+\varphi\right),
\end{aligned}
$$

where $A$ and $\varphi$ are the parameters determined by the initial conditions and $\varepsilon$ is the exponential decay rate. It can be found that the envelope of vibration attenuation of the pavement and tire conform to the relationship as shown in equation (11). The vibration attenuation equation for the pavement and tire is in the form of exponential decay. By calculating the second derivative of equation (11), the envelope of acceleration attenuation of the tire and pavement vibration can be obtained as shown in the following equation [22]:

$$
\begin{aligned}
x(t) & =A e^{-\varepsilon t}, \\
a & =\ddot{x}(t)=A \varepsilon^{2} e^{-\varepsilon t} .
\end{aligned}
$$

2.4. GCGA Method. In order to study the effect of diatomite content, basalt fibers content, and WRA content on the basic volume indexes, the pavement performance, and the vibration attenuation performance of WRM, the GCGA, a 
mathematical analysis method, is used to quantitatively analyse these experimental data [34-37]. Since different physical indicators have different physical meanings, it is necessary for all physical indicators to perform normalization processing before the GCGA. The normalization method is as the following equation:

$$
x_{i}=\frac{f_{i}-\min \left(f_{1}, f_{2}, \ldots, f_{7}\right)}{\max \left(f_{1}, f_{2}, \ldots, f_{7}\right)-\min \left(f_{1}, f_{2}, \ldots, f_{7}\right)},
$$

where $x_{i}$ is the normalization results of the experimental data $(i=1,2, \ldots, 7)$ and $f_{i}$ is the experimental data of the group $i$ asphalt mixture. A grey correlation coefficient between the reference sequence $x_{0}=\left(x_{0}(1), x_{0}(2), \ldots, x_{0}(7)\right)$ and comparative sequences $x_{j}=\left(x_{j}(1), x_{j}(2), \ldots, x_{j}(7)\right), \gamma_{j}$, is defined as the following equation:

$$
\gamma_{j}=\frac{1}{N} \sum_{k=1}^{N} \lambda_{j}(k)
$$

where $N=7$ and $\lambda_{j}(k)$ can be calculated with the following equation:

$$
\lambda_{j}(k)=\frac{\min _{j} \min _{k}\left|x_{0}(k)-x_{j}(k)\right|+0.5 \max _{j} \max _{k}\left|x_{0}(k)-x_{j}(k)\right|}{\left|x_{0}(k)-x_{j}(k)\right|+0.5 \max _{j} \max _{k}\left|x_{0}(k)-x_{j}(k)\right|} .
$$

\section{Results and Discussion}

3.1. Marshall Indexes of the Three Types of Asphalt Mixtures. According to JTG E20-2011, the VV, VMA, VFA, MS, and FL of seven groups of asphalt mixtures were tested and calculated. The calculated test results are shown in Table 6. It can be seen from Table 6 that the addition of diatomite can reduce the $\mathrm{VV}$ of asphalt mixture, while the addition of basalt fiber increases the VV of asphalt mixture. And the VMA, VFA, and MS of asphalt mixture can be increased by adding diatomite and basalt fiber. In addition, with the increase of diatomite content, VV of DWRM decreases gradually, and, with the increase of basalt fibers content, VV of BWRM increases gradually. The addition of diatomite increases the content of WRA, thus the colloid composed of asphalt and diatomite can occupy more space between the aggregates, which raises VFA of asphalt mixtures, thus reducing $\mathrm{VV}$ of asphalt mixtures. Different from this, the addition of basalt fibers increases the WRA content but hinders the compaction of the aggregate $[38,39]$, which raises VMA of asphalt mixtures; thus it can increase VV of asphalt mixtures. Furthermore, the addition of diatomite and basalt fibers can improve the Marshall stability of WRM, but the excessive basalt fibers content can have a negative impact on the stability of WRM.

3.2. Pavement Performance of Asphalt Mixtures. Table 7 shows the test results of the permanent deformation resistance at high temperature, cracking resistance at low temperature, and water damage resistance of the seven groups of asphalt mixtures, and three samples from each group were tested. It can be concluded and calculated from Table 7 that the values of the DS, $\varepsilon_{T}$, and TSR of DWRM and BWRM is larger than those of WRM. For DWRM, DS, $\varepsilon_{T}$, and TSR have increased by $53.84 \%, 33.02 \%$, and $5.31 \%$ in maximal, respectively. And the basalt fibers maximally increase those indexes by $17.65 \%, 28.15 \%$, and $8.93 \%$, respectively, which means that diatomite and basalt fibers can significantly improve the highand low-temperature performance and moisture susceptibility of WRM. In addition, it can be inferred that diatomite is superior to basalt fibers in improving high- and low-temperature performance of WRM; however, basalt fibers are superior to diatomite in improving moisture susceptibility of WRM. Moreover, it can be also found that the excessive diatomite content has a negative effect on the high- and lowtemperature performance of WRM, and the excessive basalt fibers content has a negative impact on the high-temperature performance and moisture susceptibility of WRM.

3.3. Vibration Attenuation Analysis of WRM. According to the method described in Section 2.2.3, the vibration attenuation properties of the rutting plate specimens made of seven groups of asphalt mixtures were tested. Figure 5 shows the vibration acceleration reduction curves of these rutting plate specimens after impact loading. It can be seen from Figure 5 that the amplitude of the vibration acceleration of these rutting plates is continuously decreasing with the increase of time after the impact load is applied. This is because the asphalt mixture is a viscoelastic material. After the impact loading, the amplitude of the vibration acceleration of these rutting plates continuously reduces due to the viscous damping of these asphalt mixtures.

Further, equation (12) is used to fit the envelope curves of vibration acceleration attenuation. The fitting results are also shown in Figure 5, and Figure 5(h) shows the variation of the exponential decay rate (damping coefficient $\varepsilon_{r}$ ) with the content of diatomite and basalt fibers. As can be seen from Figure 5, the correlation coefficients $R^{2}$ of exponential equation (12) for fitting the envelopes of vibration acceleration attenuation of seven groups of WRM are greater than 0.97, which shows that the exponential equation can well characterize the vibration attenuation of these asphalt mixtures. According to the fitting results of the damping coefficients $\varepsilon_{r}$, it can be calculated that, compared with WRM, the damping coefficient $\varepsilon_{r}$ of DWRM with 5 wt.\%, 7.5 wt. $\%$, and 10 wt. $\%$ diatomite and BWRM with 0.2 wt. $\%, 0.3$ wt. $\%$, and 0.4 wt. $\%$ basalt fibers increases by $40.22 \%$, $104.37 \%, 152.01 \%, 101.21 \%, 183.14 \%$, and $216.02 \%$, respectively. It can be found that the addition of diatomite and basalt fibers can significantly improve the vibration attenuation properties of WRM, and with the increase of the content of diatomite and basalt fibers, the improvement is more significant. In addition, it can be also concluded that the basalt fibers are superior to diatomite in improving the vibration attenuation properties of WRM.

3.4. Vibration Attenuation Analysis of Tires on WRM. According to the method described in Section 2.2.4, the vibration attenuation properties of the tire on the rutting plate specimens made of these asphalt mixtures were tested. 
TABLE 6: Test results of Marshall indexes for seven groups of asphalt mixtures.

\begin{tabular}{|c|c|c|c|c|c|c|}
\hline Mixtures & Content (\%) & VV (\%) & VMA (\%) & VFA (\%) & MS $(\mathrm{kN})$ & $\mathrm{FL}(\mathrm{mm})$ \\
\hline WRM & 0 & 3.6 & 14.1 & 75.0 & 14.28 & 3.26 \\
\hline \multirow{3}{*}{ DWRM } & 5 & 3.6 & 14.7 & 75.5 & 14.49 & 3.1 \\
\hline & 7.5 & 3.2 & 14.2 & 77.4 & 14.98 & 3.98 \\
\hline & 10 & 2.5 & 13.9 & 82.4 & 16.50 & 3.32 \\
\hline \multirow{3}{*}{ BWRM } & 0.2 & 3.1 & 14.2 & 78.6 & 15.23 & 3.1 \\
\hline & 0.3 & 3.6 & 14.5 & 75.2 & 15.41 & 3.69 \\
\hline & 0.4 & 3.8 & 15.2 & 75.0 & 14.79 & 3.12 \\
\hline
\end{tabular}

TABLE 7: Test results of pavement properties for seven groups of asphalt mixtures.

\begin{tabular}{|c|c|c|c|c|c|c|c|c|c|c|}
\hline \multirow{2}{*}{ Mixtures } & \multirow{2}{*}{ Content (\%) } & \multicolumn{3}{|c|}{ High-temperature performance } & \multicolumn{3}{|c|}{ Low-temperature performance } & \multicolumn{3}{|c|}{ Moisture susceptibility } \\
\hline & & $d_{1}(\mathrm{~mm})$ & $d_{2}(\mathrm{~mm})$ & DS (times/min) & $R_{T}(\mathrm{MPa})$ & $\varepsilon_{T}(\mu \varepsilon)$ & $S_{T}(\mathrm{MPa})$ & $R_{T 1}(\mathrm{MPa})$ & $R_{T 2}(\mathrm{MPa})$ & TSR (\%) \\
\hline WRM & 0 & 2.810 & 3.010 & 3150 & 3.8 & 2732 & 2376 & 14.34 & 12.69 & 88.5 \\
\hline \multirow{3}{*}{ DWRM } & 5 & 2.300 & 2.440 & 4500 & 4.1 & 3478 & 2537 & 14.49 & 13.07 & 90.2 \\
\hline & 7.5 & 2.670 & 2.800 & 4846 & 4.0 & 3634 & 2133 & 14.98 & 13.65 & 91.1 \\
\hline & 10 & 2.040 & 2.180 & 4500 & 4.0 & 2804 & 2673 & 15.96 & 14.88 & 93.2 \\
\hline \multirow{3}{*}{ BWRM } & 0.2 & 2.460 & 2.630 & 3706 & 3.9 & 3436 & 2348 & 15.23 & 14.40 & 94.6 \\
\hline & 0.3 & 2.540 & 2.710 & 3706 & 4.4 & 3490 & 2199 & 15.41 & 14.86 & 96.4 \\
\hline & 0.4 & 2.640 & 2.830 & 3316 & 4.1 & 3501 & 2110 & 14.79 & 14.05 & 95.0 \\
\hline
\end{tabular}

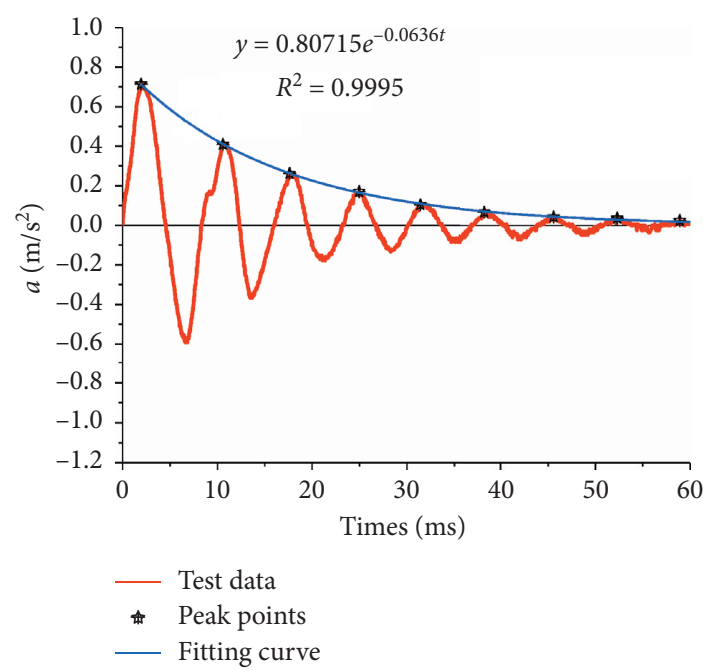

(a)

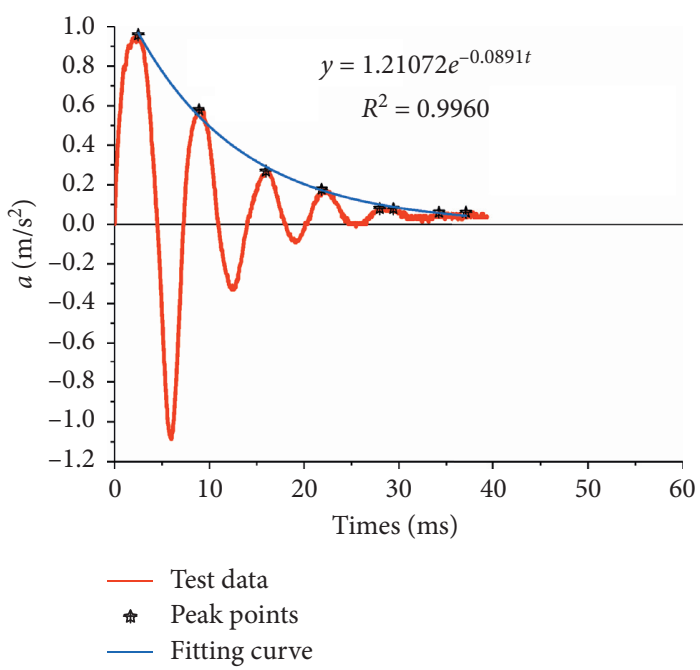

(b)

Figure 5: Continued. 


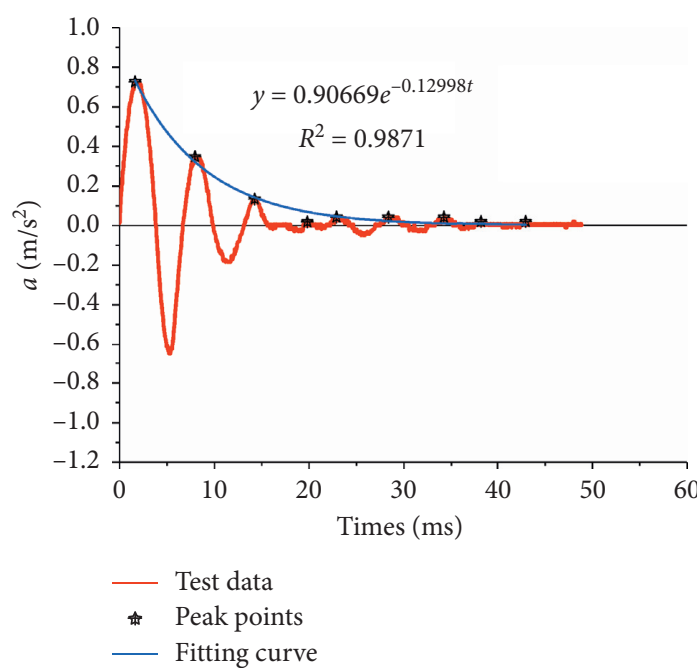

(c)

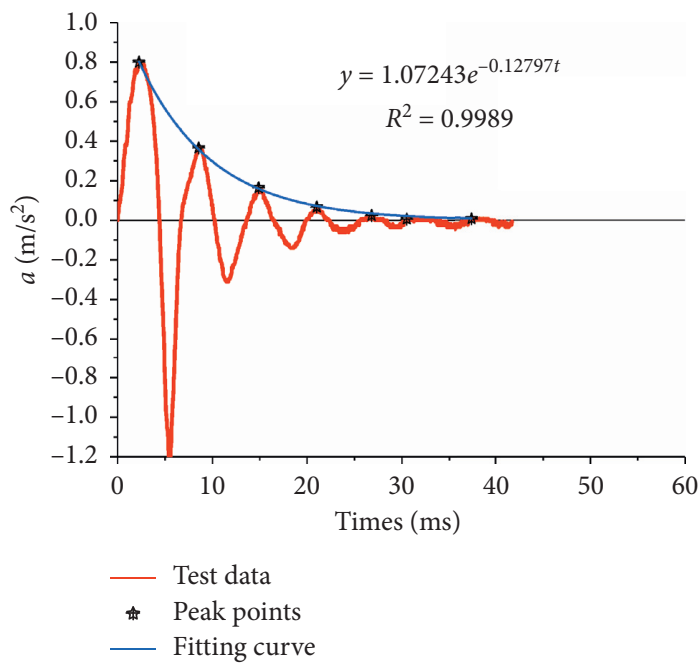

(e)

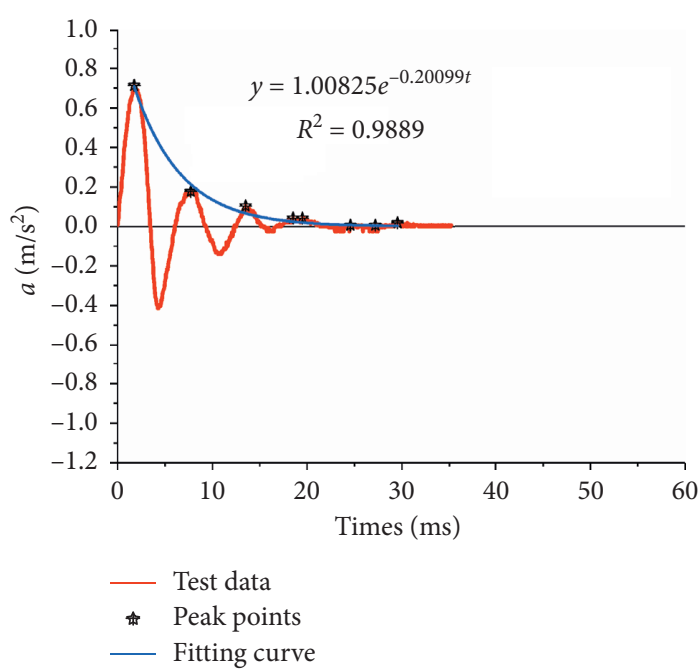

(g)

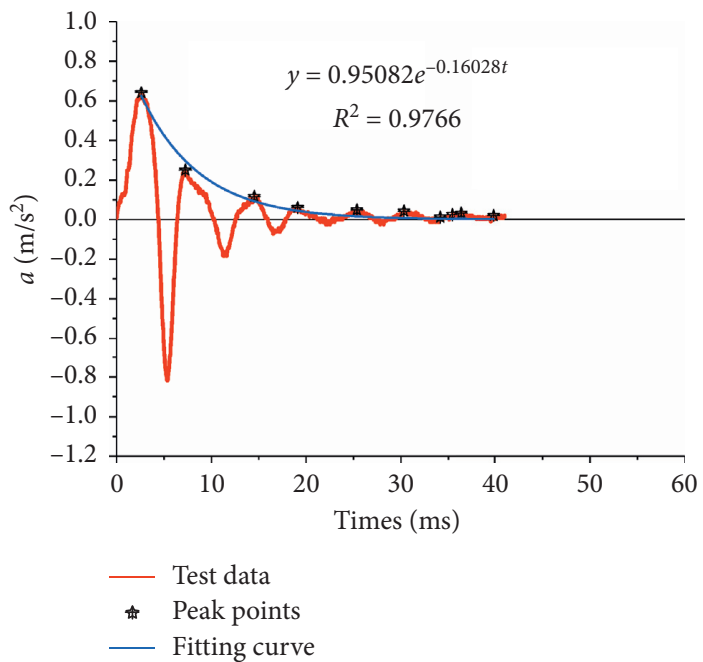

(d)

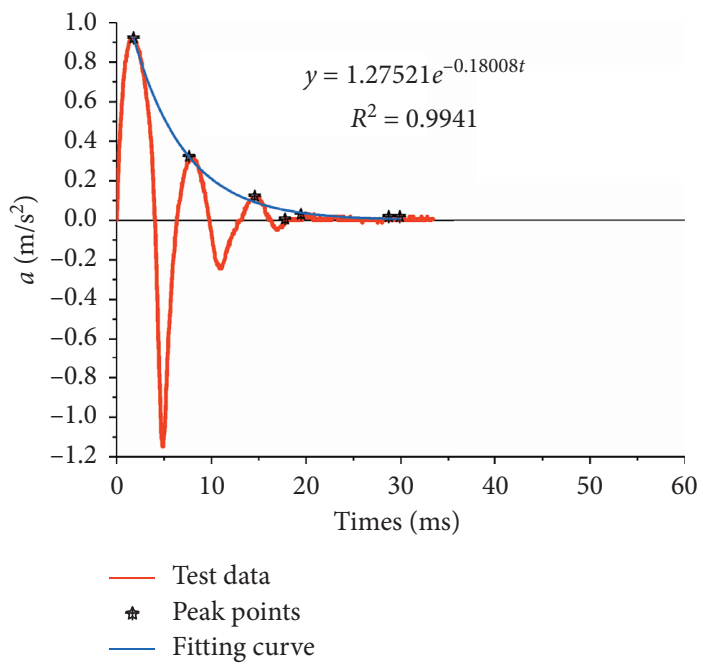

(f)

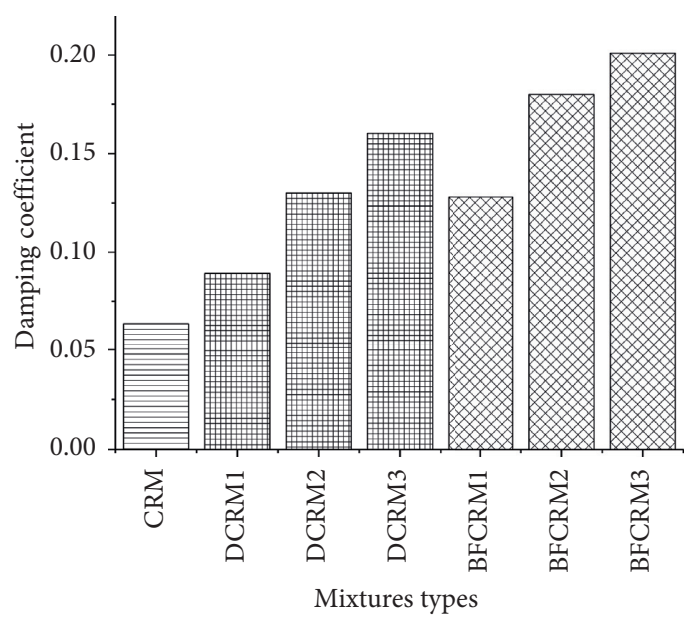

(h)

FIGURE 5: Vibration attenuation curves and damping coefficient of the rutting plates: (a) WRM; (b) DWRM with 5 wt.\% diatomite; (c) DWRM with 7.5 wt.\% diatomite; (d) DWRM with 10 wt.\% diatomite; (e) BWRM with 0.2 wt.\% basalt fibers; (f) BWRM with 0.3 wt.\% basalt fibers; (g) BWRM with 0.4 wt.\% basalt fibers; and (h) damping coefficient of the rutting plates. 


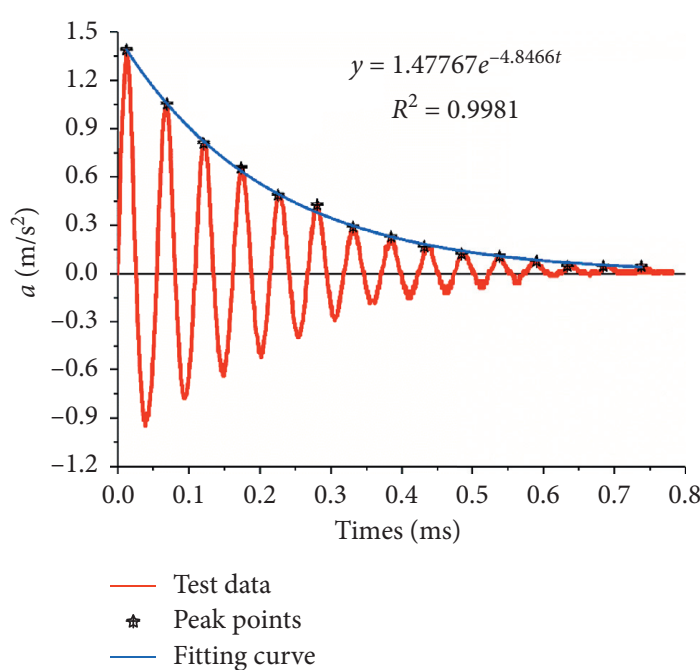

(a)

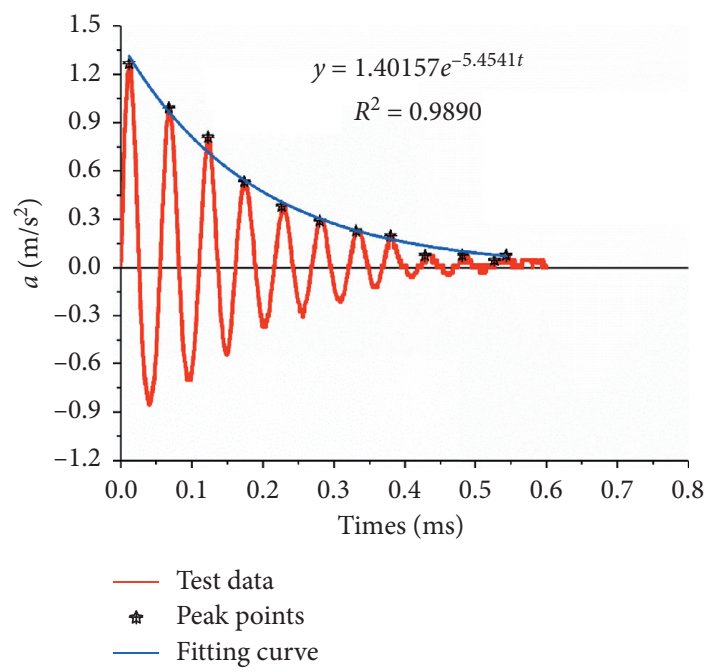

(c)

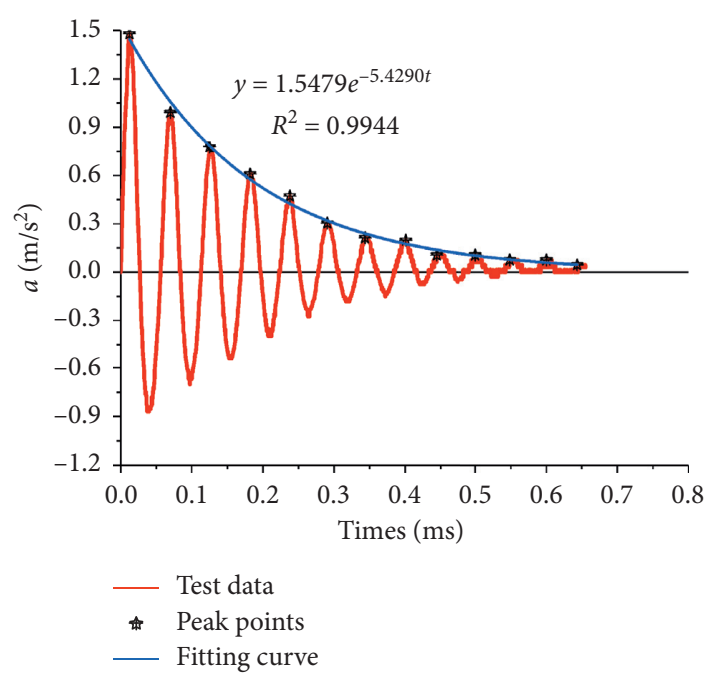

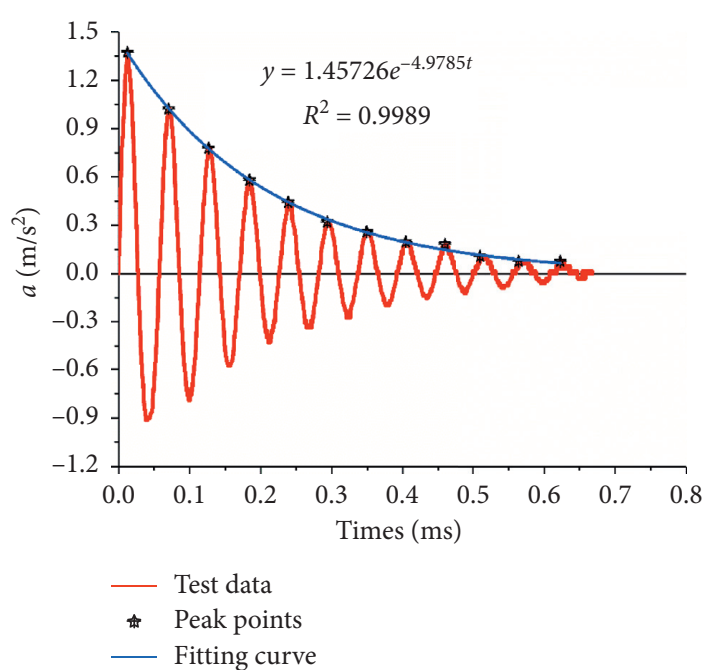

(b)

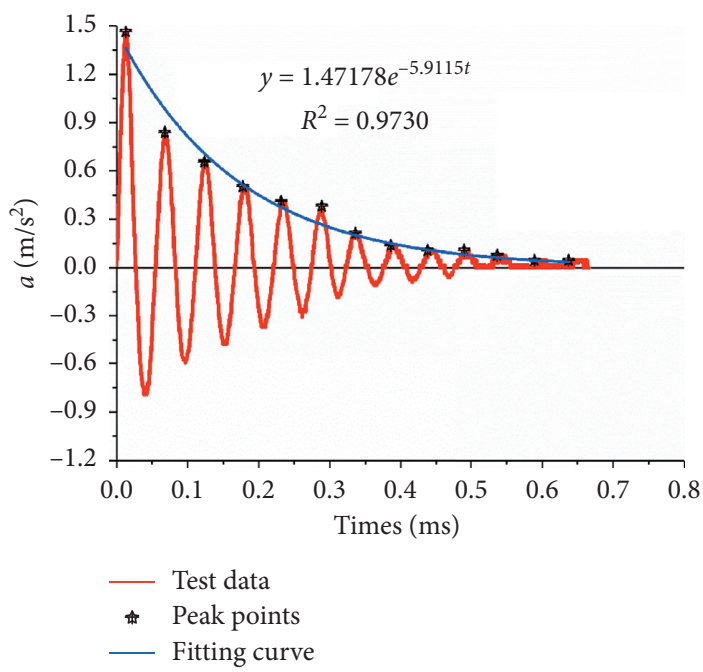

(d)

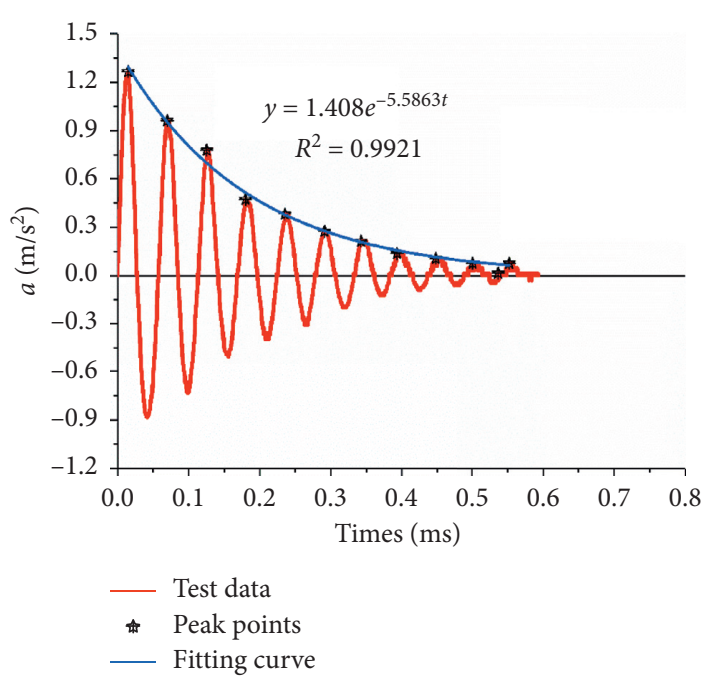

(f)

FIgURE 6: Continued. 


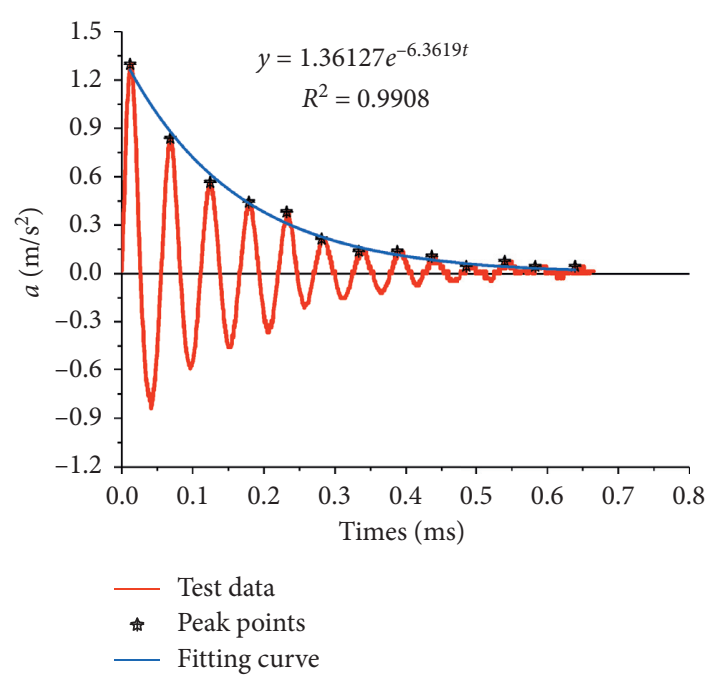

(g)

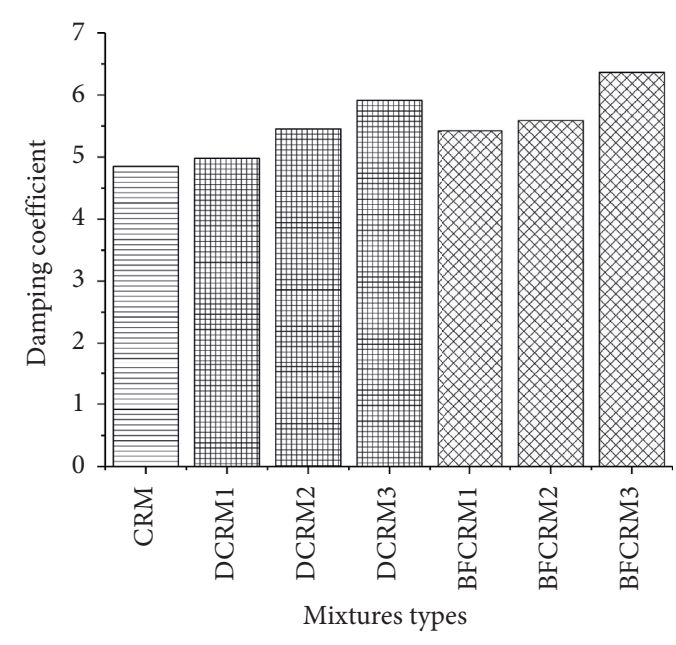

(h)

FIGURE 6: Vibration attenuation and damping coefficient of tire on the rutting plates: (a) WRM; (b) DWRM with 5 wt.\% diatomite; (c) DWRM with 7.5 wt.\% diatomite; (d) DWRM with 10 wt.\% diatomite; (e) BWRM with 0.2 wt.\% basalt fibers; (f) BWRM with 0.3 wt.\% basalt fibers; (g) BWRM with 0.4 wt.\% basalt fibers; and (h) damping coefficient of the tire.

Figures 6(a)-6(g) show the vibration attenuation curves of the tire on these rutting plate specimens after impact loading. Just as the vibration attenuation variation of the rutting plates, it can be seen from Figures 6(a)-6(g) that the amplitude of the vibration acceleration of the tire on these rutting plates is continuously decreasing with the increase of time after loading due to the damping of the tire and these asphalt mixtures.

Again, equation (12) is used to fit the envelope curves of the vibration acceleration attenuation of the tire. The fitting results are also shown in Figure 6, and Figure 6(h) shows the trend of the exponential decay rate (damping coefficient $\varepsilon_{t}$ ) with the content of diatomite and basalt fibers. It can be also found from Figure 6 that exponential equation (12) can well reflect the vibration attenuation characteristics of the tire on these asphalt mixtures.

According to the fitting results, it can be found that the damping coefficient $\varepsilon_{t}$ of the asphalt mixture can be increased by adding diatomite and basalt fiber. $10 \%$ diatomite and $20 \%$ basalt fiber can increase the damping coefficient $\varepsilon_{t}$ of asphalt mixture by $21.97 \%$ and $31.27 \%$, respectively. It can be concluded that the addition of diatomite and basalt fibers can significantly improve the vibration attenuation properties of the tire on WRM. And with the increase of the content of diatomite and basalt fibers, the damping coefficient increases continuously, and the vibration attenuation properties of the tire on the WRM are also continuously enhanced. In addition, it can be also seen that the basalt fibers are superior to diatomite in improving vibration attenuation properties of the tire on the WRM. This means that the vehicle will be more comfortable on the road made of DWRM and BWRM and will produce less road noise.

3.5. Correlation Analysis. It can be seen from the above that the addition of diatomite and basalt fibers can significantly improve the high-temperature stability, low-temperature cracking resistance, water damage resistance, and vibration damping performance of WRM. However, whether these improvements in road performance and vibration attenuation of WRM are caused by the addition of diatomite and basalt fibers or by the changes of asphalt-aggregate ratio remains to be further studied. The correlation degree between the basalt fibers content, diatomite content, as well as asphalt-aggregate ratio and the volume indexes, the pavement performance, and the vibration attenuation of WRM also needs to be further calculated and analysed. Therefore, the GCGA method is used to quantitatively calculate the correlation degree between them and analyse the internal cause of improvement of the pavement performance and the vibration attenuation for DWRM and BWRM. The dimensionless processing of these indexes is needed before GCGA. The dimensionless results of all indicators are shown in Table 8 according to equation (13). Subsequently, according to equation (14) and equation (15), the grey correlation degree $\gamma_{j}$ is calculated as shown in Table 9.

From Table 9, it can be seen that there is a large difference in the correlation degree between the basalt fibers content, diatomite content, as well as asphalt-aggregate ratio and the volume indexes, the pavement performance, and the vibration attenuation of WRM. Compared with diatomite content and asphalt-aggregate ratio, basalt fiber content has a higher correlation with the VV and VMA of WRM. However, the correlation between diatomite content and VFA is higher than that between basalt fiber content and asphalt-aggregate ratio and VFA. This means that the VV and VMA of WRM are closely related to the basalt fibers content, and the addition of basalt fibers can hinder the compaction movement of aggregate in WRM and then increase VV and VMA of WRM. And the increase of the VFA of WRM is mainly caused by the increase of diatomite content and WRA content. The colloid formed by the fine 
TABLE 8: The dimensionless results of the test indexes.

\begin{tabular}{lcccccccccccc}
\hline Groups & $D$ & $B$ & $A$ & VV & VMA & VFA & MS & DS & $\varepsilon_{T}$ & TSR & $\varepsilon_{r}$ & $\varepsilon_{t}$ \\
\hline 1 & 0 & 0 & 0 & 0.846 & 0.154 & 0 & 0 & 0 & 0 & 0 & 0 & 0 \\
2 & 0.5 & 0 & 0.375 & 0.846 & 0.615 & 0.068 & 0.095 & 0.796 & 0.827 & 0.215 & 0.186 & 0.087 \\
3 & 0.75 & 0 & 0.625 & 0.538 & 0.231 & 0.324 & 0.315 & 1 & 1 & 0.329 & 0.483 & 0.401 \\
4 & 1 & 0 & 0.875 & 0 & 0 & 1 & 1 & 0.796 & 0.08 & 0.595 & 0.704 & 0.703 \\
5 & 0 & 0.5 & 0.425 & 0.462 & 0.231 & 0.486 & 0.428 & 0.328 & 0.78 & 0.772 & 0.469 & 0.378 \\
6 & 0 & 0.75 & 0.7 & 0.846 & 0.462 & 0.027 & 0.509 & 0.328 & 0.84 & 1 & 0.848 & 0.488 \\
7 & 0 & 1 & 1 & 1 & 1 & 0 & 0.23 & 0.098 & 0.853 & 0.823 & 1 \\
\hline
\end{tabular}

Note. D: diatomite content; B: basalt fibers content; A: asphalt-aggregate ratio.

TABLE 9: The grey correlation degree of the test indexes.

\begin{tabular}{lccccccrrr}
\hline Factors & VV & VMA & VFA & MS & DS & $\varepsilon_{T}$ & TSR & $\varepsilon_{r}$ & $\varepsilon_{t}$ \\
\hline D & 0.460 & 0.563 & 0.790 & 0.687 & 0.721 & 0.537 & 0.548 & 0.588 \\
B & 0.713 & 0.740 & 0.648 & 0.676 & 0.535 & 0.690 & 0.687 & 0.776 \\
A & 0.687 & 0.680 & 0.671 & 0.739 & 0.678 & 0.660 & 0.712 & 0.849 & 0.755 \\
\hline
\end{tabular}

Note. D: diatomite content; B: basalt fibers content; A: asphalt-aggregate ratio.

diatomite adsorbing a large amount of free WRA fills the gap between the aggregates and increases VFA of WRM.

For the engineering properties of WRM, the correlation degree with MS of WRM: asphalt-aggregate ratio $>$ diatomite content $>$ basalt fibers content. Compared with the asphalt-aggregate ratio or basalt fibers content, diatomite content has a higher correlation with the DS of WRM. However, the correlation between basalt fibers content and $\varepsilon_{T}$ is higher than that between diatomite content or asphalt-aggregate ratio and $\varepsilon_{T}$. The asphalt-aggregate ratio has the highest correlation with the TSR of WRM compared to diatomite content or basalt fibers content and the TSR of WRM. This indicates that the high-temperature performance of WRM is mainly related to the asphalt-aggregate ratio and diatomite content, and the addition of diatomite increases the relative content of the structural asphalt in WRM and thus improves the resistance to permanent deformation at high temperature; the basalt fibers content mainly affects the low-temperature performance of WRM, and the reinforcement effect of basalt fibers can significantly improve the anticracking ability of WRM at low temperature; the water damage resistance of WRM is mainly related to the asphalt-aggregate ratio, and a higher asphaltaggregate ratio means more WRA to wrap aggregates, which makes it more difficult for external water to penetrate the interface between WRA and aggregates, thus improving the water damage resistance.

For the vibration attenuation of WRM, the correlation degree with $\varepsilon_{r}$ and $\varepsilon_{t}$ of WRM: asphalt-aggregate ratio $>$ basalt fibers content $>$ diatomite content. This reveals that the main material for attenuating vibration in WRM is WRA, followed by basalt fibers and finally diatomite. The improvement of the vibration damping performance of WRM by diatomite and basalt fibers is mainly attributed to the increase of asphalt-aggregate ratio caused by the addition of the two, which enhances the vibration damping performance of WRM. Besides, basalt fibers, as a reinforcement and toughening material, can rapidly spread the internal stress of the asphalt mixtures, which further improves the vibration attenuation performance of the WRM.

\section{Conclusions}

In this paper, the pavement performance and vibration attenuation of WRM were reinforced by the diatomite and basalt fibers. The effect of diatomite and basalt fibers content on the pavement performance and vibration attenuation of WRM were analysed by the tests and the GCGA method. The following conclusions can be achieved:

(1) VMA, VFA, and MS of WRM increase with the addition of diatomite and basalt fibers. While $\mathrm{VV}$ of WRM decreases with the increase of diatomite content and increases with the increase of basalt fibers content. Besides, the variety of VV and VMA of WRM are closely related to basalt fiber content, while the variety of VFA of WRM is mainly related to diatomite content and WRA content.

(2) Diatomite and basalt fibers can significantly improve the high- and low-temperature performance and water damage resistance of WRM. And the improvement of high-temperature permanent deformation resistance, low-temperature cracking resistance, and water damage resistance of WRM is mainly attributed to diatomite, basalt fibers, and asphalt-aggregate ratio, respectively.

(3) The addition of diatomite and basalt fibers can significantly reinforce the vibration attenuation properties of WRM, and with the increase of the content of diatomite and basalt fibers, the reinforcement is gradually significant. In addition, the basalt fibers are superior to diatomite in improving the vibration attenuation properties of WRM and the tire on the WRM.

(4) The improvement of the vibration damping performance of WRM by diatomite and basalt fibers is 
mainly attributed to the increase of WRA content caused by adding diatomite and basalt fibers. And the reinforcement and toughening effect of basalt fibers can further improve the vibration attenuation performance of WRM.

\section{Data Availability}

The data used to support the findings of this study are available from the corresponding author upon request.

\section{Conflicts of Interest}

The authors declare no conflicts of interest.

\section{Acknowledgments}

This research was funded by the National Natural Science Foundation of China (no. 51678271), the Transportation Innovation and Development Support (Science and Technology) Project of Jilin Province (no. 2020-3-2), and the Science Technology Development Program of the Jilin Province (no. 20160204008SF) and was supported by Graduate Innovation Fund of the Jilin University (no. 101832018C005). The authors gratefully acknowledge the financial support of the above funds and the researchers of all reports cited in our paper.

\section{References}

[1] D. Lo Presti, "Recycled tyre rubber modified bitumens for road asphalt mixtures: a literature review," Construction and Building Materials, vol. 49, pp. 863-881, 2013.

[2] M. A. Morcillo, M. E. Hidalgo, M. D. Pastrana et al., "LIFE SOUNDLESS: new generation of eco-friendly asphalt with recycled materials," Environments, vol. 6, no. 4, p. 48, 2019.

[3] X. Shu and B. Huang, "Recycling of waste tire rubber in asphalt and portland cement concrete: an overview," Construction and Building Materials, vol. 67, no. Part B, pp. 217-224, 2014.

[4] M. A. H. Al-Jumaili, "Sustainability of asphalt paving materials containing different waste materials," International Conference on Materials Engineering and Science, vol. 454, Article ID 012176, 2018.

[5] R. H. Zhang, J. Liu, J. C. Huang, and Y. Fu, "Rubber modified asphalt mixture properties and mechanical testing," Applied Mechanics and Materials, vol. 105-107, pp. 810-817, 2011.

[6] N. S. Mashaan and M. R. Karim, "Evaluation of permanent deformation of CRM-reinforced SMA and its correlation with dynamic stiffness and dynamic creep," Scientific World Journal, vol. 2013, Article ID 981637, 7 pages, 2013.

[7] N. S. Mashaan, A. H. Ali, S. Koting, and M. R. Karim, "Dynamic properties and fatigue life of stone mastic asphalt mixtures reinforced with waste tyre rubber," Advances in Materials Science and Engineering, vol. 2013, Article ID 319259, 9 pages, 2013.

[8] S. M. Asgharzadeh, J. Sadeghi, P. Peivast, and M. Pedram, "Fatigue properties of crumb rubber asphalt mixtures used in railways," Construction and Building Materials, vol. 184, pp. 248-257, 2018.

[9] S. Chen, F. Gong, D. Ge, Z. You, and J. B. Sousa, "Use of reacted and activated rubber in ultra-thin hot mixture asphalt overlay for wet-freeze climates," Journal of Cleaner Production, vol. 232, pp. 369-378, 2019.

[10] W. D. Cao, "Study on properties of recycled tire rubber modified asphalt mixtures using dry process," Construction and Building Materials, vol. 21, no. 5, pp. 1011-1015, 2007.

[11] C. M. Li, Z. R. Fan, S. P. Wu et al., "Effect of carbon black nanoparticles from the pyrolysis of discarded tires on the performance of asphalt and its mixtures," Applied Sciences, vol. 8, no. 4, p. 624, 2018.

[12] X. Zhang, B. Zhang, H. Chen, and D. Kuang, "Feasibility evaluation of preparing asphalt mixture with low-grade aggregate, rubber asphalt and desulphurization gypsum residues," Materials, vol. 11, no. 8, p. 1481, 2018.

[13] J. H. Liu, "Fatigue life evaluation of asphalt rubber mixtures using semi-circular bending test," Advanced Materials Research, vol. 255-260, pp. 3444-3449, 2011.

[14] A. R. Pasandín and I. Pérez, "Fatigue performance of bituminous mixtures made with recycled concrete aggregates and waste tire rubber," Construction and Building Materials, vol. 157, pp. 26-33, 2017.

[15] A. Subhy, D. Lo Presti, and G. Airey, "Evaluation of the fracture performance of different rubberised bitumens based on the essential work of fracture," Engineering Fracture Mechanics, vol. 179, pp. 203-212, 2017.

[16] B. V. Kök, M. Yilmaz, and A. Geçkil, "Evaluation of lowtemperature and elastic properties of crumb rubber- and SBSmodified bitumen and mixtures," Journal of Materials in Civil Engineering, vol. 25, no. 2, pp. 257-265, 2013.

[17] F. Gong, S. Guo, S. Chen, Z. You, Y. Liu, and Q. Dai, "Strength and durability of dry-processed stone matrix asphalt containing cement pre-coated scrap tire rubber particles," Construction and Building Materials, vol. 214, pp. 475-483, 2019.

[18] H. B. Liu, L. X. Fu, Y. B. Jiao, H. Liu, and J. Tao, "Short-term aging effect on properties of sustainable pavement asphalts modified by waste rubber and diatomite," Sustainability, vol. 9, no. 6, p. 996, 2017.

[19] R. Maharaj, C. Maharaj, and A. Hosein, "Performance of waste polymer modified road paving materials," Progress in Rubber Plastics and Recycling Technology, vol. 34, no. 1, pp. 19-33, 2018.

[20] X. Yang, Z. You, D. Perram et al., "Emission analysis of recycled tire rubber modified asphalt in hot and warm mix conditions," Journal of Hazardous Materials, vol. 365, pp. 942-951, 2019.

[21] P. Polaczyk, B. Han, B. Huang, X. Jia, and X. Shu, "Evaluation of the hot mix asphalt compactability utilizing the impact compaction method," Construction and Building Materials, vol. 187, pp. 131-137, 2018.

[22] T. Real, L. Montalbán, C. Masanet, and J. Real, "New laboratory procedure using a modal approach to obtain vibration attenuation properties of unaged and aged asphalt mixtures," Proceedings of the Institution of Mechanical Engineers, Part L: Journal of Materials: Design and Applications, vol. 230, no. 2, pp. 627-639, 2016.

[23] K. P. Biligiri, "Effect of pavement materials' damping properties on tyre/road noise characteristics," Construction and Building Materials, vol. 49, pp. 223-232, 2013.

[24] M. Ameri, M. Reza Seif, M. Abbasi, and A. Khavandi Khiavi, "Viscoelastic fatigue resistance of asphalt binders modified with crumb rubber and styrene butadiene polymer," Petroleum Science and Technology, vol. 35, no. 1, pp. 30-36, 2017.

[25] S. Aflaki and M. Memarzadeh, "Using two-way ANOVA and hypothesis test in evaluating crumb rubber modification (CRM) agitation effects on rheological properties of bitumen," 
Construction and Building Materials, vol. 25, no. 4, pp. 2094-2106, 2011.

[26] L. Zhang, C. Xing, F. Gao, T.-s. Li, and Y.-q. Tan, "Using DSR and MSCR tests to characterize high temperature performance of different rubber modified asphalt," Construction and Building Materials, vol. 127, pp. 466-474, 2016.

[27] Research Institute of Highway Ministry of Transport, "Standard test methods of bitumen and bituminous mixtures for highway engineering," China communications Press, Beijing, China, JTG E20-2011 in Chinese, 2011.

[28] Z. Lv, "Study on road performance and vibration and noise reduction performance of diatomite-basalt fiber compound modified asphalt mixture," MS thesis, Jilin University, Jilin, China, 2019.

[29] Y. Cheng, L. Li, Y. Zhang, Z. Lv, and C. Zhu, "Quantitative analysis of effect and interaction of diatomite and basalt fiber on asphalt performance," Journal of Materials in Civil Engineering, vol. 31, no. 12, Article ID 04019306, 2019.

[30] Y. C. Cheng, L. L. Li, P. L. Zhou, Y. Zhang, and H. Liu, "Multiobjective optimization design and test of compound diatomite and basalt fiber asphalt mixture," Materials, vol. 12, no. 9, 1461 pages, 2019.

[31] R. Xiong, J. Fang, A. Xu, B. Guan, and Z. Liu, "Laboratory investigation on the brucite fiber reinforced asphalt binder and asphalt concrete," Construction and Building Materials, vol. 83, pp. 44-52, 2015.

[32] J. Gao, A. Sha, Y. Huang et al., "Cycling comfort on asphalt pavement: influence of the pavement-tyre interface on vibration," Journal of Cleaner Production, vol. 223, pp. 323-341, 2019.

[33] S. J. Hong, S.-W. Park, and S. W. Lee, "Tire-pavement noise prediction using asphalt pavement texture," KSCE Journal of Civil Engineering, vol. 22, no. 9, pp. 3358-3362, 2018.

[34] D. Zhang, M. Chen, S. Wu et al., "Analysis of the relationships between waste cooking oil qualities and rejuvenated asphalt properties," Materials, vol. 10, no. 5, p. 508, 2017.

[35] Z. Wang, Q. Wang, and T. Ai, "Comparative study on effects of binders and curing ages on properties of cement emulsified asphalt mixture using gray correlation entropy analysis," Construction and Building Materials, vol. 54, pp. 615-622, 2014.

[36] J.-c. Du and M.-F. Kuo, "Grey relational-regression analysis for hot mix asphalt design," Construction and Building Materials, vol. 25, no. 5, pp. 2627-2634, 2011.

[37] J. Gao, H. Wang, Z. You et al., "Gray relational entropy analysis of high temperature performance of bio-asphalt binder and its mixture," International Journal of Pavement Research and Technology, vol. 11, pp. 698-708, 2018.

[38] Y. Zheng, Y. Cai, G. Zhang, and H. Fang, "Fatigue property of basalt fiber-modified asphalt mixture under complicated environment," Journal of Wuhan University of TechnologyMaterials Science Edition, vol. 29, no. 5, pp. 996-1004, 2014.

[39] N. Morova, "Investigation of usability of basalt fibers in hot mix asphalt concrete," Construction and Building Materials, vol. 47, pp. 175-180, 2013. 